\title{
Urological Cancer Treatment by a Multidisciplinary Team throughout the Covid-19 Pandemic: What Have We Learned?
}

\section{Tratamiento del cáncer urológico por un equipo multidisciplinario durante la pandemia de Covid-19: ¿Qué hemos aprendido?}

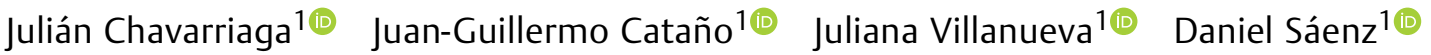 \\ Daniel Suso-Palau ${ }^{1}$ Santiago Rodríguez ${ }^{10}$ Catalina Villaquiran ${ }^{1}$ Juan Galvis ${ }^{20}$ Paola Pinilla ${ }^{3}$ \\ Angélica Morales ${ }^{1}$ German Patiño ${ }^{10}$
}

\footnotetext{
${ }^{1}$ Division of Urological Oncology, Hospital Universitario San Ignacio, Pontificia Universidad Javeriana, Bogotá, Colombia

2 Division of Radiotherapy, Hospital Universitario San Ignacio,

Pontificia Universidad Javeriana, Bogotá, Colombia

${ }^{3}$ Division of Oncology, Hospital Universitario San Ignacio, Pontificia

Universidad Javeriana, Bogotá, Colombia
}

Address for correspondence Juliana Villanueva, MD, Hospital
Universitario San Ignacio, Carrera 7, No. 40-62. Bogotá, Colombia (e-mail: julianavillanueva@javeriana.edu.co).

\begin{abstract}
Keywords

- Covid-19

- urologic surgical procedures

- pandemics

- urology

- urologic neoplasms

- medical practice management

Introduction It is known that cancer care is best approached by a multidisciplinary team (MDT). This became specifically true in the Covid-19 pandemic in which choices for urological cancer treatment are influenced by many factors. In some cases, delayed treatment may have consequences regarding the patient's oncological outcomes. The aim of the present article is to report our experience throughout the Covid-19 pandemic treating patients with urological neoplasms at a high-volume center.

Methods We used a convenience sampling method. Cases were evaluated and discussed on an individual basis at the MDT meetings, and, after a consensus regarding delaying or scheduling treatment, patients were scheduled according to the risk of postponing the procedures. The Medically Necessary, Time-Sensitive (MeNTS) scoring system was measured in each patient; all patients answered the Centers for Disease Control and Prevention (CDC) Covid-19 self-screening questionnaire prior to surgery. The Covid-19-free survival rate was estimated.

Results A total of 194 patients were assessed by the multidisciplinary team and finally treated, with median follow-up of 4 (interquartile range [IQR]: 2.75 to 6 ) months. Only two patients had Covid-19 confirmed by real-time polymerase chain reaction (RT-PCR). In total, 54 patients underwent oncological surgery, 129 were treated with radiotherapy, and 11 were treated with intravenous chemotherapy. The median age was 66 years
\end{abstract}

received

December 17, 2020

accepted

March 8, 2021
DOI https://doi.org/

10.1055/s-0041-1731414. ISSN 0120-789X.

e ISSN 2027-0119. (c) 2021. Sociedad Colombiana de Urología. All rights reserved. This is an open access article published by Thieme under the terms of the Creative Commons Attribution-NonDerivative-NonCommercial-License, permitting copying and reproduction so long as the original work is given appropriate credit. Contents may not be used for commercial purposes, or adapted, remixed, transformed or built upon. (https://creativecommons.org/ licenses/by-nc-nd/4.0/)

Thieme Revinter Publicações Ltda., Rua do Matoso 170, Rio de Janeiro, RJ, CEP 20270-135, Brazil 


\section{Resumen}

Palabras clave
- infecciones por
coronavirus
- procedimientos
quirúrgicos
urológicos
- pandemias
- urología
- neoplasias urológicas
- administración de la
práctica médica

(IQR: 59 to 94 years), and the median MeNTS score in the surgically-treated cohort was 35 points (IQR: 31 to 47 points).

Conclusions The evaluation and treatment of urological cancer should be conducted by an MDT; this is of utmost importance, especially during the Covid-19 pandemic. The data collected in our institution showed that most patients could be safely treated by taking all necessary precautions and discussing each case individually in the MDT meetings and performing a close follow-up.

Introduccion La atención del cáncer se aborda mejor con un equipo multidisciplinario (EMD), aspecto que se tornó más importante en la pandemia por Covid-19, en que las opciones para tratar el cáncer urológico están influenciadas por muchos factores. En algunos casos, el tratamiento retrasado puede tener consecuencias en los resultados oncológicos del paciente. El objetivo de este estudio es describir nuestra experiencia en un centro de referencia y de alto volumen para el tratamiento de neoplasias urológicas durante la pandemia por Covid-19.

Métodos Realizamos un muestreo por conveniencia. Posteriormente, los casos fueron evaluados y discutidos de forma individual en las reuniones del EMD. Posterior a la obtención de un consenso sobre el tratamiento del paciente, los pacientes fueron programados según el riesgo individual de posponer el manejo. Se midió la puntuación de cada paciente en el sistema Medically Necessary Time-Sensitive (MeNTS, "Médicamente necesario, sensibles al tiempo"). Todos los pacientes respondieron el cuestionario de autoevaluación del Centers for Disease Control and Prevention (CDC) COVID-19 antes de la cirugía. Se estimó la tasa de supervivencia libre de Covid-19.

Resultados Un total de 194 pacientes fueron evaluados por el EMD y finalmente tratados, con una mediana de seguimiento de 4 (rango intercuartil [RIC]: 2,75 a 6) meses. Solo dos tenían Covid-19 confirmado por reacción en cadena de la polimerasa en tiempo real (RCP-TR). Un total de 54 pacientes fueron sometidos a cirugía oncológica, 129 fueron tratados con radioterapia, y 11 fueron tratados con quimioterapia intravenosa. La mediana de edad fue de 66 años (RIC: 59 a 94 años), la puntuación mediana en el MeNTS de la cohorte tratada quirúrgicamente fue de 35 puntos (RIC: 31 a 47 puntos).

Conclusiones La evaluación y el tratamiento del cáncer urológico debe ser realizado por un EMD durante la pandemia de Covid-19. Los datos recopilados en nuestra institución mostraron que la mayoría de los pacientes podrian ser tratados de manera segura, discutiendo cada caso individualmente y haciendo un seguimiento cercano.

\section{Introduction}

The coronavirus disease 2019 (COVID-19) pandemic is the largest pandemic of the century, characterized by influenzalike symptoms (ILSs) and, if severe, it can induce a severe respiratory compromise requiring ventilation, admission to the intensive care unit (ICU), and leading to death in 3\% to $5 \%$ of the infected patients. At the time the present article was written, more than 108 million people had been infected, and $2,373,205$ people had died of the disease worldwide. ${ }^{1-5}$

Resource allocation has become necessary to overcome the crisis that the pandemic has caused in health systems worldwide due to shortages in health care practitioners and ventilators for critically-ill patients. Most of the elective urological surgeries had to be postponed during the pandemic. $^{5-10}$ A global predictive model estimated that 28.4 million operations will be canceled or delayed, and, of these, 2.3 million would be cancer-related surgeries. Cancelling elective surgery will have a major impact on patients and cumulative, potentially devastating consequences to health care systems. $^{11}$

The best care for urological cancer patients has been described when approached by a multidisciplinary team (MDT), particularly prostate cancer (PCa), which all guidelines recommend. ${ }^{9,10,12}$ This became specifically true in the Covid-19 pandemic, in which the choices for urological 
cancer treatment are not only influenced by oncologic criteria, and, in some cases, a delay in treatment may have consequences regarding the oncological outcomes. ${ }^{9,10,12-14}$

We aim to report our MDT experience during the Covid-19 pandemic, to describe the oncological outcomes and the Covid-free survival rate of our patients treated surgically, with radiotherapy, or with cytotoxic chemotherapy from March to September 2020, in a high-volume center which has treated over 3 thousand patients with confirmed Covid-19.

\section{Methods}

On March 6th, 2020, the first confirmed case of severe acute respiratory syndrome coronavirus 2 (SARS-CoV2) case was reported in Colombia. On March 24th, the government declared a mandatory lockdown at a national level which was withdrawn on September 1st. All urological elective surgeries scheduled for that time frame were canceled. We continued to treat patients with urological malignancies with an MDT. We performed an observational descriptive study, and used a convenience sampling method to gather our subjets.

\section{Study Population}

The present study was conducted as part of a transition plan in which an MDT for genitourinary malignancies composed by urological oncology, radiotherapy, clinical oncology, palliative care, orthopedic oncology, radiology, genetics, functional urology, andrology, and a specialized nurse who reviewed and approached all genitourinary cancer cases treated at the institution. The MDT continued to meet virtually on a weekly basis throughout the pandemic. All new patients, challenging cases and surgical cases were discussed before deciding on the treatment.

\section{End-Points and Assessments}

We used the Medically Necessary, Time-Sensitive (MeNTS) scoring system developed by Pranchard et al., ${ }^{8}$ a novel scoring system to prioritize medically-necessary operations that should not be delayed due to the Covid-19 pandemic. The scoring system comprehends 21 plausible factors contributing to poorer perioperative outcomes, risk of SARSCoV2 transmission to healthcare professionals, and increased hospital resource utilization during the pandemic, with values anchors assigned to a 1-to-5 scale based on objective measures. $^{8}$ When calculating the MeNTs score, we established a predefined score to each procedure in a general meeting of the MDT, and a cut-off value of 45 points was determined and gradually adjusted throughout the pandemic, according to the occupation of the Intensive Care Unit (ICU) and the resources available. We also considered the guidelines for Covid-19 management of the European Association of Urology (EAU)'s Guideline Office Rapid Reaction Group (GORRG) and Robotic Urology Section (ERUS), as well as and the Recommendations for Tiered Stratification of Urological Surgery Urgency in the Covid-19 Era reported by the Cleveland Clinic Department of Urology. ${ }^{12-14}$
All cases were evaluated and discussed on an individual basis at the MDT meetings, and, after consensus, the patients were gradually scheduled for surgery according to the risk of deferring the procedures. An electronic database of all patients was created, the score on the American Society of Anesthesiologists (ASA) Physical Status Classification System was calculated based on preoperative anesthesia consultations. The patients were initially screened for influenza-like illness symptoms, and all answered the Centers for Disease Control and Prevention (CDC) Covid-19 screening questionnaire prior to surgery, radiation therapy or chemotherapy. Throughout the pandemic, all patients scheduled for oncological surgery were required to have a negative SARS-CoV-2 real-time polymerase chain reaction (RT-PCR) diagnostic panel 48 hours prior to surgery.

The Covid-19 screening questionnaires were applied by phone call, and if the patient reported they had been diagnosed with Covid-19, tailored questions regarding the time and method of diagnosis were asked.

\section{Statistical Analysis}

For the descriptive analysis of the variables, proportions, central tendency measures (median and mean) and dispersion (standard deviation [SD], interquartile range [IQR]) were used. The Covid-19-free survival rate was evaluated, as well as the incidence and time at risk. The STATA (StataCorp, LLC, College Station, TX, US) software, version 14.0, was used for the statistical calculations.

\section{Results}

A total of 194 patients were assessed by the MDT and finally treated: from March 6th to September 1st, 2020, 54 patients underwent oncological surgery, and 56 procedures were performed; 129 were treated with radiotherapy (RT), 82 were treated with curative-intent RT, and 47 received palliative RT; 11 patients were treated with intravenous chemotherapy, 6 for metastatic castration-resistant prostate cancer (MCRPC), 2 with neoadjuvant chemotherapy (NAC) for muscle-invasive bladder cancer (MIBC), 1 with adjuvant chemotherapy (AC) for upper-tract urothelial carcinoma (UTUC), and 2 with palliative chemotherapy for MIBC and UTUC ( - Table 1). The oncological diagnosis and staging are shown in (-Table 2.)

The median age of the sample was of 66 years (IQR: 59 to 94 years), and the ASA classification was: ASA I - 11 (19.2\%) patients; ASA II - 27 (47.3\%) patients; and ASA III -20 (35\%) patients. The median MeNTS score in the surgically-treated cohort was of 35 points (IQR 31 to 47 points); 53 patients had a MeNTS score below 45 points, and only 1 had a score above 45 , but this patient had been diagnosed with MIBC and was advised to undergo radical cystectomy and heterotopic urinary diversion with an ileal conduit, which was carried without complications (-Table 3). Among the patients not infected by SARS-CoV-2, 7.7\% had obstructive sleep apnea (OSA), 5.8\% had lung disease, including asthma, chronic obstructive pulmonary disease (COPD), and cystic fibrosis (CF), 11.8\% had diabetes, $5.8 \%$ were immunocompromised, 
Table 1 Treatment modality

\begin{tabular}{|l|l|}
\hline Treament modality & $n$ \\
\hline Radiotherapy & 129 \\
\hline Palliative & 47 \\
\hline Curative-intent (prostate cancer) & 82 \\
\hline Chemotherapy & 11 \\
\hline Metastatic castration-resistant prostate cancer & 6 \\
\hline Neoadjuvant chemotherapy for bladder cancer & 2 \\
\hline $\begin{array}{l}\text { Adjuvant chemotherapy for Upper-tract } \\
\text { urothelial carcinoma }\end{array}$ & 1 \\
\hline Palliative chemotherapy & 2 \\
\hline Oncological surgery & 54 \\
\hline Partial penectomy or glansectomy & 3 \\
\hline Diagnostic ureteroscopy & 1 \\
\hline Radical cystectomy & 3 \\
\hline Partial cistectomy & 1 \\
\hline Radical epididimectomy & 1 \\
\hline Radical orchiectomy & 2 \\
\hline Transurethral resection of bladder tumor & 14 \\
\hline Laparoscopic radical nephrectomy & 9 \\
\hline Open radical nephrectomy & 2 \\
\hline Open partial nephrectomy & 2 \\
\hline Laparoscopic radical nephroureterectomy & 2 \\
\hline Open radical nephroureterectomy & 11 \\
\hline Open radical prostatectomy +extended & 3 \\
\hline Simple orchiectomy (prostate cancer) & 194 \\
\hline Total & ckp \\
\hline
\end{tabular}

Abbreviations: ePLND, extended pelvic lymph node dissection; mCRPC, metastatic castration resistant prostate cancer; NAC, neoadjuvant chemotherapy; PCa, Prostate cancer; TURBT, transurethral resection of bladder tumor; UTUC, upper tract urothelial carcinoma.

and $50 \%$ had cardiovascular disease (hypertension, cardiac failure or coronary disease). The two patients who were confirmed to have had COVID-19 had multiple comorbidities, all had COPD, OSA, and the patient who died was diabetic and had hypertension.

The patients were followed up for a median of 4 (IQR: 2.75 to 6 ) months, and contacted by phone to ascertain whether they had had Covid-19 or ILSs; only 3 patients reported they had symptoms: 2 complained of a cough, and 1, of shortness of breath; 2 of them had Covid-19 confirmed by RT-PCR. One of these patients who had been diagnosed with MIBC and was treated with radical cystoprostatectomy died from Covid-19-related severe acute respiratory distress, which he acquired 92 days after surgery. (-Table 2 ) Two patients reported that had had contact to with a known COVID-19 positive person in the previous 14 days: they were screened with RT-PCR and did not test positive. The analysis of the Covid-19-free survival rate showed a median time
Table 2 Oncological diagnosis and pathological stage

\begin{tabular}{|l|l|}
\hline Total & $\boldsymbol{n}=194$ \\
\hline Penile cancer & 2 \\
\hline pT2 cNOMO & 1 \\
\hline pT1a cNOMO & 1 \\
\hline Prostate cancer & 148 \\
\hline Localized & 70 \\
\hline Locally-advanced & 23 \\
\hline Metastatic prostate cancer & 55 \\
\hline Bladder cancer & 22 \\
\hline Non-muscle-invasive bladder cancer & 14 \\
\hline Muscle-invasive bladder cancer & 6 \\
\hline Metastatic prostate cancer & 2 \\
\hline Upper-tract urothelial carcinoma & 6 \\
\hline Localized & 5 \\
\hline Locally-advanced & 1 \\
\hline Renal-cell carcinoma & 13 \\
\hline pT1a & 1 \\
\hline pT1b & 2 \\
\hline pT2a & 5 \\
\hline pT2b & 1 \\
\hline pT3a & 3 \\
\hline pT4 & 1 \\
\hline Germ-cell testicular tumors & 2 \\
\hline pT1NOM0 & 1 \\
\hline pT2NOM0 & 1 \\
\hline Epididymal tumor & 1 \\
\hline
\end{tabular}

Abbreviations: NMBIC, non-muscle invasive bladder cancer; MIBC, muscle invasive bladder cancer; PCa, prostate cancer.

at risk of 76.5 (IQR: 11 to 166) days, and the estimated incidence of Covid-19 cases was of 0,004/persons-day during the follow-up.

\section{Discussion}

The patients were always informed about the risk of SARSCoV-2 infection during their treatment and agreed to undergo surgery, RT or chemotherapy knowing the potential risks and associated complications. We intended to have the shortest possible length of hospital stay for all postoperative patients, all measures were taken to prevent the transmission of SARS-CoV-2, such as independent and individual access to the operating rooms (ORs), chemotherapy and RT suites, independent elevators to move patients scheduled for elective surgery, specific and isolated ORs for Covid-19 patients, limited time in the recovery room, and specific wards for surgical patients. Early recovery after surgery (ERAS) protocols were encouraged. For laparoscopic surgeries, we used trocars with 
214 Urological Cancer Treatment by a Multidisciplinary Team throughout the Covid-19 Pandemic Chavarriaga et al.

Table 3 Clinical and sociodemographic characteristics of the patients undergoing oncologic surgeries

\begin{tabular}{|c|c|c|}
\hline \multirow[t]{2}{*}{ Variables } & \multicolumn{2}{|c|}{ Covid-19 diagnosis confirmed by PCR } \\
\hline & Yes & No \\
\hline Total (n) & 2 & 52 \\
\hline \multicolumn{3}{|l|}{ Sociodemographics } \\
\hline \multicolumn{3}{|l|}{ Gender (\%) } \\
\hline Male & $50 \%$ & $80.8 \%$ \\
\hline Female & $50 \%$ & $19.2 \%$ \\
\hline \multicolumn{3}{|l|}{ Age (years) } \\
\hline Quartile 1 & 73 & 56.5 \\
\hline Quartile 2 & 73 & 65 \\
\hline Quartile 3 & 73 & 72 \\
\hline \multicolumn{3}{|l|}{ Clinical features } \\
\hline \multicolumn{3}{|l|}{ ASA Physical Status Classification System (\%) } \\
\hline 1 & $0 \%$ & $21.2 \%$ \\
\hline II & $50 \%$ & $46.1 \%$ \\
\hline III & $50 \%$ & $32.7 \%$ \\
\hline \multicolumn{3}{|l|}{ MeNTS Score } \\
\hline Mean (standard deviation) & $40(1.4)$ & $34.2(5.7)$ \\
\hline \multicolumn{3}{|l|}{ Self-Screening CDC COVID-19 (\%) } \\
\hline Fever & $0 \%$ & $1.9 \%$ \\
\hline Cough & $50 \%$ & $0 \%$ \\
\hline Shortness of breath & $0 \%$ & $1.9 \%$ \\
\hline Odynophagia & $0 \%$ & $0 \%$ \\
\hline Vomiting/Diarrhea & $0 \%$ & $0 \%$ \\
\hline Contact with people with Covid-19 in the last 14 days & $50 \%$ & $1.9 \%$ \\
\hline Quarantine & $50 \%$ & $0 \%$ \\
\hline \multicolumn{3}{|l|}{ Covid-19 test } \\
\hline$R T-P C R$ & $100 \%$ & $1.9 \%$ \\
\hline Antibodies & $0 \%$ & $0 \%$ \\
\hline \multicolumn{3}{|l|}{ Comorbidities } \\
\hline OSA & $100 \%$ & $7.7 \%$ \\
\hline Lung disease (asthma, COPD, CF) & $100 \%$ & $5.8 \%$ \\
\hline Cardiovascular disease (HTN, CHF, CAD) & $50 \%$ & $50 \%$ \\
\hline Type-2 diabetes mellitus & $50 \%$ & $11.5 \%$ \\
\hline Immunocompromised* & $100 \%$ & $5.8 \%$ \\
\hline Death (\%) & $50 \%$ & $0 \%$ \\
\hline
\end{tabular}

Abbreviations: ASA, American Society of Anesthesiologists; CAD, coronary artery disease;CDC, Centers for Disease Control and Prevention; CF, cystic fibrosis; CHF, congestive heart failure; COPD, chronic obstructive pulmonary disease; HTN, hypertension; PCR, polymerase chain reaction; RT-PCR, real-time polymerase chain reaction; MenTS, Medically Necessary, Time-Sensitive scoring system; OSA, obstructive sleep apnea.

Note: *Hematologic malignancy, stem cell transplant, solid organ transplant, active/recent cytotoxic chemotherapy, anti-tumor necrosis factor alpha or other immunosuppressants, $>20 \mathrm{mg}$ predinisone equivalent/day, congenital immunodeficiency, hypogammaglobulinemia on intravenous immunoglobulins, and AIDS.

one-way valves, connected the smoke evacuator to one of the ports, and set a pneumoperitoneum pressure below $12 \mathrm{mmHg}$.

Urological cancer care should be conducted by a MDT, specially during the Covid-19 pandemic. This approach has proven to be valuable and of utmost importance when deciding which treatments should be prioritized and which could safely be delayed. In our MDT, we evaluated and treated 194 patients for 6 months, and took all necessary precautions to avoid the transmission of Covid-19. 
An MDT for PCa management and their experience with the highest level of Covid-19 infection in Italy were reported by Sciarra et al. ${ }^{10}$ They reported an almost complete interruption in the determiation of prostate-specific antigen (PSA) for early diagnosis, and a significant reduction in prostate biopsy procedures; a reduction of $63.6 \%$ in radical prostatectomy (RP) and of $84.6 \%$ in external-beam radiotherapy (EBRT) was also described. ${ }^{10}$ They also found that the only management that did not suffer a significant reduction was cytotoxic therapy for metastatic hormone-sensitive or castration-resistant Pca, given that the authors considered both non-deferrable. ${ }^{10}$ The criteria for undeferrable RT or RP patients were Glasgow Scale $(G S) \geq 7(4+3)$ or $\mathrm{cT} 3$ or $\mathrm{N}+$. They concluded that an MDT evaluation should be implemented whenever possible to assign the most appropriate treatment to patients and to better balance the oncologic and Covid-19 restraint needs. ${ }^{10}$ All the patients with PCa finally treated with curative intent had an International Society of Urological Pathology (ISUP) grade $\geq 2$ $(4+3)$ or were cT3 or $\mathrm{N}+$.

In a narrative review of key studies published since April 2020, Wallis et al. ${ }^{9}$ discussed the risks of deferring treatment for genitourinary cancers during the Covid-19 pandemic. They concluded that the treatment of patients with T1/T2 renal masses could be safely deferred, while locally-advanced renal tumors $(\geq \mathrm{T} 3)$ should be treated promptly, and they recommended that patients with metastatic renal cell carcinoma (RCC) of poor risk (according to the International Metastatic RCC Database Consortium [IMDC]) may consider tyrosine kinase inhibitors over immunotherapy, given that they are less likely to require toxicity-related hospitalization or glucocorticoids than immunotherapeutic regimens. ${ }^{9}$ All of the patients with RCC surgically treated by our MDT had locally advanced renal tumors ( $\geq$ T3), except for one with Stauffer syndrome variant with jaundice, who required emergency surgery. The UTUC treatment depends on grade and stage. Patients with low-grade UTUC are often managed with nephron-sparing approaches, and thus are likely to have minimal to no risk with a surgical delay. In patients with high-grade disease, delays of up to 12 weeks may not be associated with changes in survival, at a cost of worse pathologic outcomes. ${ }^{9}$ Patients with low-grade nonmuscle-invasive bladder cancer (NMIBC) are unlikely to suffer from a delay of 3 to 6 months, but patients with MIBC are at risk of disease progression with radical cystectomy delays beyond 12 weeks since the diagnosis or incompletion of the neoadjuvant chemotherapy. Cases of UTUC and MIBC were treated in a timely manner at our institution. The $\mathrm{RP}$ of most patients with intermediate and high-risk PCa can be deferred for three to six months without change in outcomes, and RT should be administered with neoadjuvant androgen deprivation therapy (ADT), which could help delay the RT initiation by three to six months. Wallis et al. ${ }^{9}$ recommend avoiding surgical delays for radical orchiectomy, and they also recommend surveillance should be the preferred choice for patients with clinical stage-I disease. There is insufficient data to provide guidance on the effects of delaying postchemotherapy retroperitoneal lymph node dissection (RPLND); despite this, patients with intermediate and poor-prognosis metastatic giant-cell tumors (GCTs) should undergo chemotherapy without delay. Lack of information regarding the risk of delayed intervention in penile carcinoma was found; regardless of that, inguinal lymphadenectomy, when indicated, must be performed within three months of treating the primary lesion. ${ }^{9}$

Another narrative review of the literature evaluating published data on delaying urological cancer surgery was published by Tachibana et al. ${ }^{14}$ Their results were quite similar to those of the study by Wallis et al. ${ }^{9}$ They recommended that delays in the treatment of MIBC should be shorter than 10 weeks, and neoadjuvant chemotherapy should be considered; UTUC patients should also be treated sooner than three months after the diagnosis, and high-risk patients, especially those with ureteral tumors, should undergo adjuvant chemotherapy.

Patients with $\geq$ T2 RCC should be considered for early surgery. Adrenal, testicular and penile cancers are aggressive, and should be treated in a timely manner, as indicated. ${ }^{14}$ For PCa care, the literature has a significant variability regarding safe delay times and some articles indicate that delays of 60 days may affect recurrence-free survival; Ginsburg et al. ${ }^{13}$ found no significant difference in the odds of adverse pathology, upgrading, positive nodes or secondary treatments with a delay of up to 12 months. High-risk PCa patients need to be treated within 3 months of the diagnosis, and neoadjuvant ADT prior to RT does not negatively impact the oncologic outcomes. ${ }^{14}$

Campi et al. ${ }^{15}$ assessed the burden of non-deferrable urological cancer surgery in Italy. They assessed the yearly proportion of high-priority major surgeries at three Italian high-volume centers. Of 2,387 cancer surgeries, $32.3 \%$ were non-deferrable, and accounted for $12.6 \%$ of the cases of radical nephroureterectomy, $17.3 \%$ of the cases of nephrectomy, $33.9 \%$ of the cases of RP, and $36.2 \%$ of the cases of radical cystectomy; unfortunately, $26.4 \%$ of these procedures were performed in patients with an ASA classification $\geq 3$. With this data, more than $2 / 3$ of major urological cancer surgeries could be postponed, apparently without compromising oncological outcomes. ${ }^{15}$

The strengths of the present study are: the report of the experience of an MDT specialized in urological cancer care during the largest pandemic of the century; the description of the impact on MDT care regarding treatment decisionmaking, which has proven to be remarkable at this period; and the evaluation of the transmission of Covid-19 and the rate of infection in the treated population. The present study has several limitations, namely the retrospective and unicentric nature of it; moreover, there hasn't been a predefined threshold value for the MeNTS cumulative score, and we arbitrarily decided to establish a cut-off value $\geq 45$ points to consider postponing surgical procedures. Another limitation is that some patients were not initially screened for SARSCoV-2 with the RT-PCR diagnostic panel, given the lack of availability of tests at the beginning of the pandemic in our country. All patients were contacted until this manuscript was written, and the lack of long-term follow-up is another limitation of the study. 


\section{Conclusion}

The evaluation and treatment of urological cancer should be conducted by an MDT; this is currently the standard of care for cancer patients: all individuals with urological cancer should be referred to an MDT evaluation to ensure the optimal clinical care. Careful selection of oncological treatments is critical in the challenging health care situation caused by the Covid-19 crisis, and our real-life data showed that most patients could be safely treated taking all necessary precautions and reviewing and discussing each case individually in the MDT meetings. This is of utmost importance, specially during the Covid-19 pandemic, given that most choices of treatment are not only influenced by oncologic criteria; instead, resources and the availability of health caregivers availability are the major influencers in treatment decision-making, and, in some cases, delays in the treatment may have consequences on the oncological outcomes.

Ethics Approval and Consent to Participate The present article was approved by the ethics committee on human research of Pontificia Universidad Javeriana under IRB \#2020428-267.

\section{Availability of Data and Materials}

The datasets used and/or analyzed during the current study can be made available by the corresponding author upon reasonable request.

\section{Conflict of Interests}

The authors have no conflict of interests to declare.

\section{References}

1 Ma X, Ph D, Wang D, Ph D, Xu W, Wu G, et al. A Novel Coronavirus from Patients with Pneumonia in China, 2019. 2020:727-33

2 Lipsitch M, Phil D, Swerdlow DL, Finelli L. Defining the Epidemiology of Covid-19 - Studies Needed. 2020:26-8

3 Emilia R, Academy O, Lieve O, Hospital V, Grande A, Metropolitano O, et al. COVID-19 and Urology: A Comprehensive Review of the Literature. https://doi.org/10.1111/bju.15071
4 Medica EM, Ficarra V, Novara G, Abrate A, Bartoletti R, Crestani A, et al. Urology practice during the COVID-19 pandemic. 2020. Doi: 10.23736/S0393-2249.20.03846-1

5 Simonato A, Giannarini G, Abrate A, Bartoletti R, Crestani A, Nunzio $\mathrm{CDE}$, et al. Clinical pathways for urology patients during the COVID19 pandemic. 2020. Doi: 10.23736/s0393-2249.20.03861-8

6 Iscaife A, Marchini GS, Srougi V, et al. The urologist's role in the fight of COVID-19 pandemic: mandatory mindset shift on the frontline. Int Braz J Urol 2020;46(05):879-882. Doi: 10.1590/ s1677-5538.ibju.2020.0316

7 Vigneswaran Y, Prachand VN, Posner MC, Matthews JB, Hussain M. What Is the Appropriate Use of Laparoscopy over Open Procedures in the Current COVID-19 Climate? J Gastrointest Surg 2020;24(07): 1686-1691. Doi: 10.1007/s11605-020-04592-9

8 Prachand VN, Milner R, Angelos P, et al. Medically Necessary, Time-Sensitive Procedures: Scoring System to Ethically and Efficiently Manage Resource Scarcity and Provider Risk During the COVID-19 Pandemic. J Am Coll Surg 2020;231(02):281-288. Doi: 10.1016/j.jamcollsurg.2020.04.011

9 Wallis CJD, Novara G, Marandino L, et al. Risks from Deferring Treatment for Genitourinary Cancers: A Collaborative Review to Aid Triage and Management During the COVID-19 Pandemic. Eur Urol 2020;78(01):29-42. Doi: 10.1016/j.eururo.2020.04.063

10 Sciarra A, Salciccia S, Maggi M, et al. Elective procedures for prostate cancer in the time of Covid-19: a multidisciplinary team experience. Prostate Cancer Prostatic Dis 2020;19-21:1-3. Doi: 10.1038/s41391-020-0240-4 [Internet]

11 Negopdiev DCOVIDSurg Collaborative. Elective surgery cancellations due to the COVID-19 pandemic: global predictive modelling to inform surgical recovery plans. Br J Surg 2020;107(11):1440-1449. Doi: 10.1002/bjs.11746

12 Assi T, Ibrahim N, Abboud RK, Kattan C, Rassy E, Nemr E, et al. The management of patients with metastatic prostate cancer during the COVID-19 pandemic. 2020. https://doi.org/10.2217/fon2020-0361

13 Ginsburg KB, Curtis GL, Timar RE, George AK, Cher ML. Delayed Radical Prostatectomy is Not Associated with Adverse Oncologic Outcomes: Implications for Men Experiencing Surgical Delay Due to the COVID-19 Pandemic. J Urol 2020;204(04):720-725. Doi: 10.1097/JU.0000000000001089

14 Tachibana I, Ferguson EL, Mahenthiran A, et al. Delaying Cancer Cases in Urology during COVID-19: Review of the Literature. J Urol 2020;204(05):926-933. Doi: 10.1097/JU.0000000000001288

15 Campi R, Amparore D, Capitanio U, et al. Assessing the Burden of Nondeferrable Major Uro-oncologic Surgery to Guide Prioritisation Strategies During the COVID-19 Pandemic: Insights from Three Italian High-volume Referral Centres. Eur Urol 2020;78(01):11-15 